\title{
SIMULATION OF SMALL-SIZE MILKING MACHINE VACUUM SYSTEM
}

\author{
Oleksandr Medvedskyi ${ }^{1}$, Savelii Kukharets ${ }^{1}$, Jonas Cesna ${ }^{2}$, Olena Sukmaniuk ${ }^{1}$ \\ ${ }^{1}$ Polissia National University, Ukraine; ${ }^{2}$ Vytautas Magnus University, Lithuania \\ aleksmedvedsky@gmail.com, saveliy_76@ukr.net, jonas.cesna@vdu.lt, \\ sukmanyukolena@gmail.com
}

\begin{abstract}
Small-size milking machines of well known firms differ in the parameters of a vacuum system. Different schemes and techniques are used to connect the vacuum system components into one construction. It affects the variability of the performance figures of the equipment operation. It appears to be difficult to determine the generalized parameters of a vacuum system. Various components of a construction scheme of a vacuum system cause different loss levels of the vacuum pressure. Significant pressure losses in a vacuum system reduce the energetic effectiveness of a milking machine. The researchers have not sufficiently studied the problem of a vacuum system simulation with minimal vacuum pressure losses. A need arises to substantiate the rational construction of a vacuum system of a small-size milking machine. For this purpose, it is necessary to study the schemes of connecting a vacuum pump, a vacuum tank, air lines and a milk bucket into an overall design. The connection of the matched as to the geometric parameters components results in reducing the pressure losses in the vacuum system. The reducing of pressure losses in the vacuum system makes it possible to increase the level of vacuum pressure in the milk bucket. Herewith, the vacuum pump capacity is not changed. The investigation proves that it is expedient to attach the air pipeline under minimum angle to the cylinder of the vacuum tank. It makes it possible to reduce the vacuum pressure losses by 10-45\%. It has been established that pressure losses reduce due to the increase in the size of an opening, when the set angle of the air pipeline connected to the vacuum tank decreases. The investigation establishes the increase in pressure losses by $8-11 \%$ for the air line with an optimal bending radius. A mathematical model of determining pressure at the inlet of the main air pipeline of the vacuum pump has been received. A rational scheme of the vacuum system of a small-size milking machine has been substantiated.
\end{abstract}

Keywords: vacuum tank, main air-pipeline, vacuum pump, structural scheme, pressure losses.

\section{Introduction}

Small-size milking machines have an identical set of vacuum system components: a vacuum pump, a vacuum pipeline, a vacuum tank, a milking unit and a milk bucket. But machine models differ in technological, design and geometric parameters of the components. Overall total of a vacuum system determines the level of vacuum pressure in a vacuum system. The mismatch of design parameters and technological operating conditions causes pressure fluctuations in the vacuum system [1]. Excess fluctuation pressure results in lower milk cow productivity and poorer health [2-4]. The level of pressure fluctuation must meet the requirements of ISO [5], irrespective of the design and technological parameters. It concerns a minimal duration of regaining pressure in the vacuum system [6]. Different schematic illustrations and techniques of connecting components into one construction of a vacuum system have been used. The researchers point out the necessity to correlate the vacuum pump capacity and the vacuum system capacity admittance $[7 ; 8]$. Series of connection schemes of the vacuum system components have been studied in the investigation [6]. But a suggested scheme has not been introduced in commercial models of small-size milking machines because of its complexity.

Optimum size of a vacuum tank and of a milk bucket, under which pressure fluctuations are minimal, has been recommended by the researchers [9]. Herewith, the researchers point out the reduction of duration of the working pressure setting under the condition of increasing the vacuum system admittance, as well as of analogical vacuum pump capacity. These demands ensure a higher level of constant vacuum pressure [9]. But the studies, as to the effects of the techniques of connecting components into one construction on the effectiveness of a vacuum system, have not been conducted. Thus, there is a need to design a constructive schematic illustration, which will ensure maximal geometric admittance of a vacuum system. In this case, lower level of pressure losses under the same vacuum pump capacity can be achieved.

\section{Materials and methods}

The goal of the research is to determine the effects of different techniques of connecting components of a vacuum system into one construction on the level of pressure losses. To achieve the goal, it is necessary to simulate the effects of constructive schematic illustrations of a vacuum system on its 
admittance. The theory of mathematic simulation, with due regards to essentials of integral and differential computations, hydro and gas dynamics, as well as to vacuum machinery, has been used during the research. The object of the research is structural and functional schemes of connecting the components of a vacuum system.

A vacuum system combines the components which facilitate the performance of a small-size milking machine with given operational conditions. First of all, it is providing of a required level and stability of vacuum pressure. In its turn, the stability of vacuum pressure is determined by minimal pressure losses during the milking machine performance. That is why constructive and geometric specifications of its structural and functional schemes can be of great importance for more effective machine milking. Thus, the investigation is topical and important for determining the reserves of reducing pressure losses. Small-size milking machines of well-known firms-producers have different structural schemes and vacuum system parameters. A significant difference is in the technique of connecting the vacuum pump and thevacuum pipeline with the vacuum tank (Fig. 1).
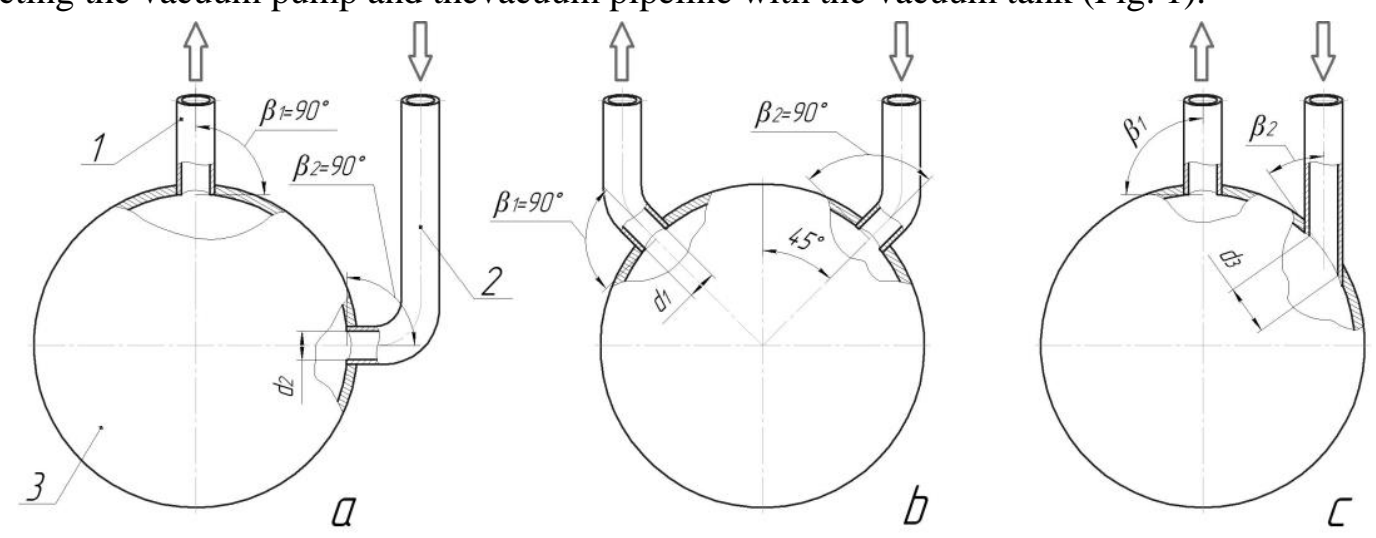

Fig. 1. Schemes of attaching a vacuum pump and a vacuum pipeline to a vacuum tank of smallsize milking machines: $a$-Bosio MMU11 and UID-10; $b$-MobiMelk; $c$-Melasty; 1 -tubulure of vacuum pump; 2 -vacuum pipeline; 3 -vacuum tank (authors' research)

According to Fig.1, the tubulure of the vacuum pump and the vacuum pipeline are attached to the vacuum tank in different ways. The machines Bosio MMU11 and UID-10 have a similar angle $\beta_{1}=\beta_{2}=90^{\circ}$ of attaching the vacuum pump sockets and the vacuum pipeline to the vacuum tank. Such a scheme is a logical one as to a reasonable connecting of a vacuum pump and a vacuum tank. A smallsize mobile milking machine MobiMelk has another connection scheme under the same angle $\beta_{1}=\beta_{2}=90^{\circ}$. For the machine Melasty, the angle $\beta_{2}$ of thevacuum pipeline is less than $90^{\circ}$, and for the vacuum pump socket $\beta_{1}=90^{\circ}$, like for the machine Bosio MMU11. Such peculiarity causes the need for further studies of the effectiveness of the suggested solutions.

To estimate the total pressure losses, it is necessary to set the distribution of absolute values of pressure in the vacuum system. Each construction element of the vacuum system causes resistance to the air flow. That is why the pressure at the outlet must be higher than at the inlet of the vacuum system. Final pressure can be determined by $[7 ; 8]$ :

$$
p_{f}=p_{b}+\Delta p_{\Sigma},
$$

where $p_{f}-$ pressure at the outlet of the vacuum system, $\mathrm{Pa}$;

$p_{b}$ - pressure at the inlet of the vacuum system, $\mathrm{Pa}$;

$\Delta p_{\Sigma}-$ total pressure losses in order to lower the resistance of construction elements, $\mathrm{Pa}$.

With due regard to stationary air flow $[7 ; 10]$, the pressure at the outlet of air pipelines of the vacuum system can be determined by:

$$
p_{f}=\frac{p_{b} \cdot Q_{b}}{U_{\Sigma}}+p_{b},
$$

where $Q_{b}$-total air loss at the inlet of the vacuum system, $\mathrm{m}^{3} \cdot \mathrm{s}^{-1}$;

$U_{\Sigma}$ - total vacuum system conductivity, $\mathrm{m}^{3} \cdot \mathrm{s}^{-1}$. 
Pressure at the outlet of the vacuum system can be determined by dependence (2). With this in mind, it is necessary to assemble the vacuum system with the elements which are characterized by the highest transfer admittance.

\section{Results and discussion}

Pressure, where a socket (Fig. 1) is attached to the vacuum tank, is determined by equation (2) and recommendations $[7 ; 8]$ :

$$
p_{b p}=p_{p}+S_{p}\left(\frac{1}{U_{l 1}}+\frac{1}{U_{h 1}}\right),
$$

where $p_{p}$ - pressure at the inlet of the vacuum pump, $\mathrm{Pa}$;

$S_{p}$ - air flow through the vacuum pump pipe, $\mathrm{Pa} \cdot \mathrm{m}^{3} \cdot \mathrm{s}^{-1}$

$U_{l 1}$ - conductivity of the vacuum pump pipe, $\mathrm{m}^{3} \cdot \mathrm{s}^{-1}$;

$U_{h 1}$ - conductivity at the pipe inlet, $\mathrm{m}^{3} \cdot \mathrm{s}^{-1}$.

Pressure in a hole section, with consideration of Klaiperon-Mendeleev equation and recommendations [7; 10], is determined like:

$$
p_{h 1}=p_{l 1}+\Delta p_{h 1}=p_{l 1}+2.83 \cdot 10^{-3} \frac{S_{p}^{2}}{p_{l 1} \cdot d_{1}^{4} \cdot T} \xi_{h 1},
$$

where $p_{h 1}$ - pressure in the hole $d_{1}$ (Fig. 1), Pa;

$p_{l 1}$ - pressure at the pipe outlet, $\mathrm{Pa}$;

$\Delta p_{h 1}$ - pressure losses when lowering the hole resistance, $\mathrm{Pa}$;

$d_{1}$ - diameter of the pipe of the vacuum pump, m;

$\xi_{h 1}$ - coefficient of local resistance at the inlet of the hole, [11].

Resistance coefficient in the hole $d_{1}$ (Fig. 1) depends on a scheme of attaching to the vacuum tank with due consideration of recommendations [11]:

$$
\xi_{h 1}=0.5+0.3 \cos \beta_{1}+0.2 \cos ^{2} \beta_{1},
$$

where $\beta_{1}$-angle of attaching the pipe to the cylinder of the vacuum tank, degree.

The calculations done by formula (5) show that the resistance coefficient of the hole $\xi_{h 1}$ increases when the angle $\beta_{1}$ decreases. According to equation (4), pressure losses depend on the size of the hole $d_{1}$ (Fig. 2).

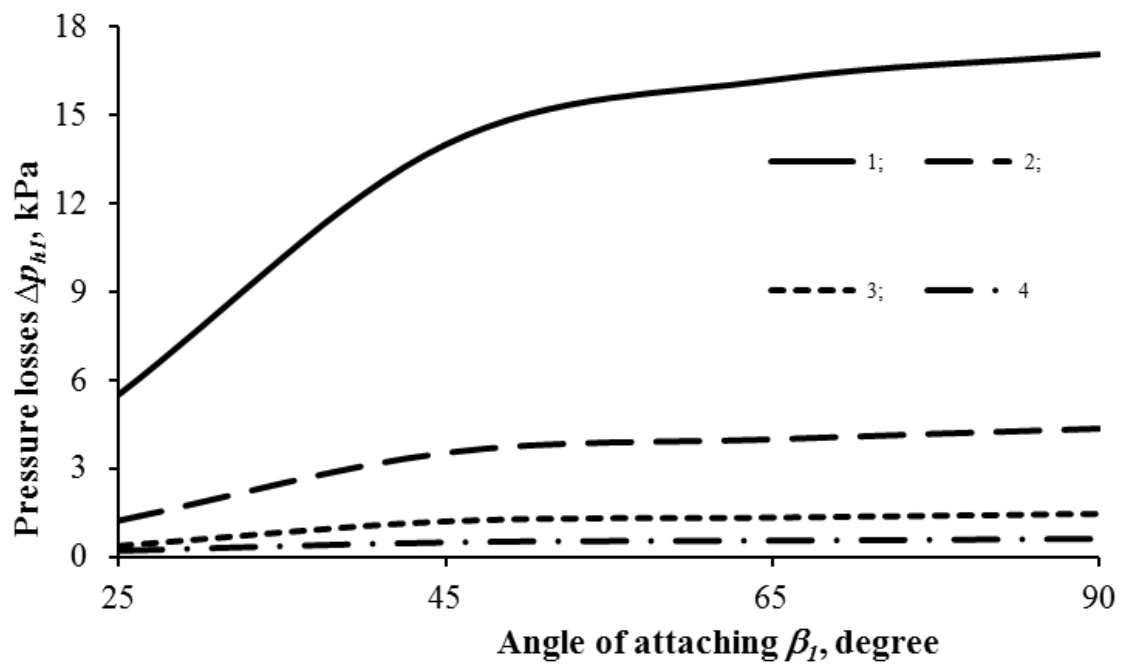

Fig. 2. Dependence of pressure losses $\Delta p_{h 1}$ at the inlet of the hole on the angle $\beta_{1}$ of attaching tubulure to the vacuum tank for pipe diameter: $1-d_{1}=10 \mathrm{~mm} ; 2-d_{1}=15 \mathrm{~mm} ; 3-d_{1}=20 \mathrm{~mm}$; $4-d_{1}=25 \mathrm{~mm}$ (authors' research) 
According to Fig. 2, when the hole diameter $d_{1}=10 \mathrm{~mm}$, pressure losses are the highest. When the attachment angle changes from $\beta_{1}=90^{\circ}$ to $\beta_{1}=25^{\circ}$, pressure losses reduce by $11 \mathrm{kPa}$. It can be explained by the fact that when the angle of an aggregate decreases $\beta_{1}$, the cross section area of the hole increases. When the hole diameter $d_{1}$ increases, pressure losses decrease irrespective of the angle $\beta_{1}$. In vacuum systems of small-size aggregates UID, Bosio and Melasty the connection of the vacuum pump and vacuum tank is made by means of a pipeline under the angle of $\beta_{1}=90^{\circ}$. For the milking machine MobiMelk, the pipeline has a flexion with some flexion radius (Fig. 1, b). It causes additional pressure losses, because the run increases by an equivalent constituent. Smaller attachment angle $\beta_{1}$ contributes to lower pressure losses in the hole; thus, total air pipeline admittance increases.

The conductivity of the air pipeline, which connects the vacuum pump and the vacuum tank, is determined on the basis of recommendations $[7 ; 8]$ by the formula:

$$
U_{l p}=\frac{1}{\left(\frac{1}{U_{l 1}}+\frac{1}{U_{h 1}}\right)}=\frac{S_{p}}{p_{h 1}-p_{p}},
$$

where $U_{l p}$-total conductivity of the air pipeline as long as $l_{1}, \mathrm{~m}^{3} \cdot \mathrm{s}^{-1}$.

Herewith, geometrical parameters and construction specifications of the air pipeline have significant impact on its admittance (Fig. 3).

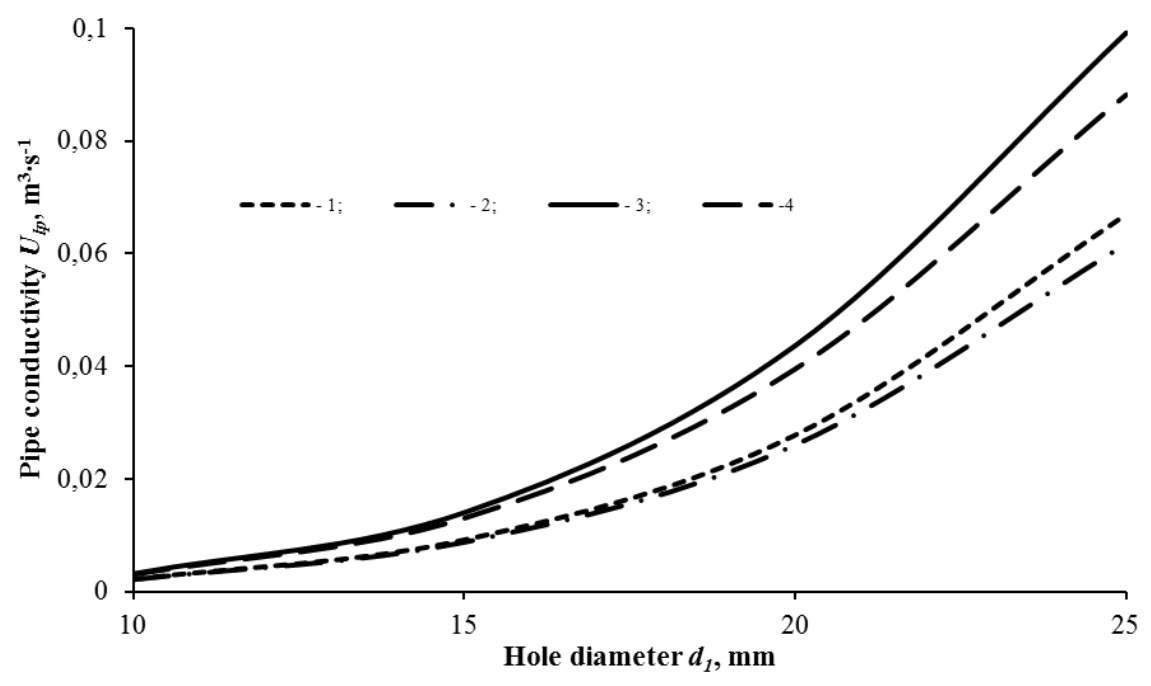

Fig. 3. Dependence of the air pipeline conductivity on geometric parameters and techniques of attaching to the vacuum tank: 1 - in-line air pipeline under the angle of $\beta_{1}=90^{\circ} ; 2$ - air pipeline with a flexion under an angle of $\beta_{1}=90^{\circ} ; 3-$ in-line air pipeline under an angle of $\beta_{1}=25^{\circ}$; 4 - air pipeline with a flexion under an angle of $\beta_{1}=25^{\circ}$ (authors' research)

When the air pipeline diameter increases (Fig. 3), its admittance increases as well. It can be explained by the reduction of pressure losses over its length. At the attachment angle of $\beta_{1}=45^{\circ}$ the conductivity increases by $9-10 \%$, and under $\beta_{1}=25^{\circ}$ it increases by $42-45 \%$ as compared to $\beta_{1}=90^{\circ}$. It happens because pressure losses at the inlet of the hole reduce. A flexion of the pipeline with a particular flexion radius increases the pressure losses by $1.5-2 \%$ over the air pipeline length. The admittance of such air pipeline decreases by $8-11 \%$, as compared to an in-line air pipeline of the same length.

The research shows that geometrical parameters of the air pipeline elements and vacuum system schemes have a significant impact on total pressure losses. The paper suggests an improved constructive scheme of a vacuum system of a small-size milking machine UID-10 (Fig. 4). The experimental investigations were conducted in order to estimate the effectiveness of an improved version. The angle of attaching air pipelines (of different diameters) to the vacuum tank and to the milk bucket was measured by means of the main independent factors. Strain-gage pressure sensors IPD-2-0.06, a comparison unit with an enhancer TOPAS 3-0.2 and a self-recording unit H-3021-3 were used. The investigations were conducted with a threefold frequency under the vacuum pressure level $-50 \mathrm{kPa}$. 


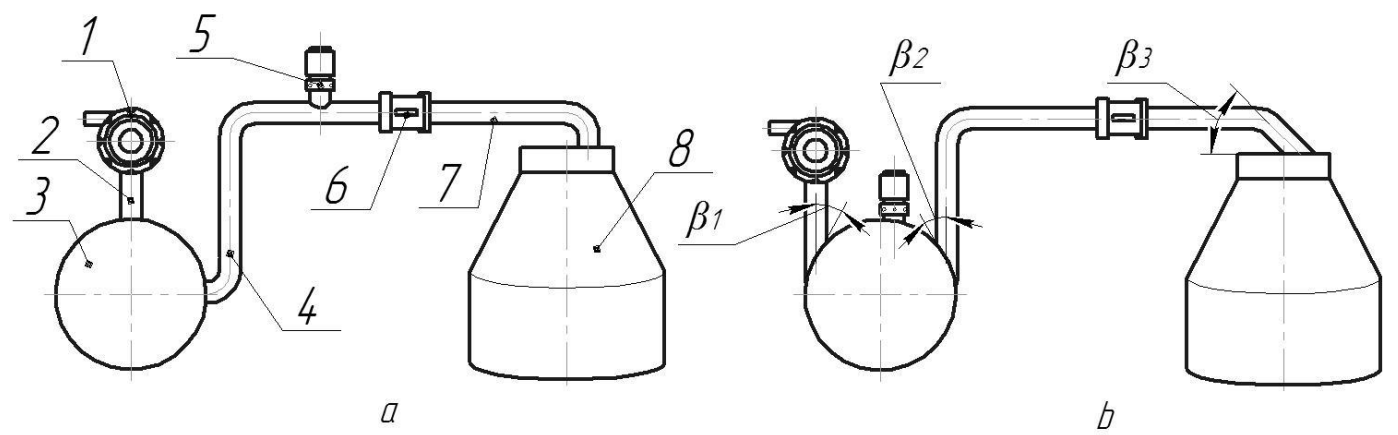

Fig. 4. Test-schemes of a vacuum commercial system $(a)$ and of an improved version $(b)$ of a small-size machine UID-10: 1 - vacuum pump; 2 - air pipeline $l_{1}$ long; 3 - vacuum tank; 4 - air pipeline $l_{2}$ long; 5 - vacuum regulator; 6 - vacuum tap; 7 - vacuum tube $l_{3}$ long; 8 - milk bucket (authors' research)

The research results were processed by means of generally available software. Regression equations $(7 ; 8)$ and dependence diagrams (Fig. 5) were received for the test-schemes of the vacuum system. The determination coefficient $R^{2}=0,999$ points to a very important functional interconnection of the variables, so we have got a high confidence of regression equations.

$$
\begin{aligned}
& U_{U I D-10}=0.0022 d^{2}-0.005 d+0.0037, \\
& U_{N E W}=0.0027 d^{2}-0.0058 d+0.0043,
\end{aligned}
$$

where $U_{U I D-10}-$ conductivity of the vacuum system UID-10 $\left(\beta_{1}=90^{\circ}, \beta_{2}=90^{\circ}\right.$ and $\left.\beta_{3}=90^{\circ}\right)$, $\mathrm{m}^{3} \cdot \mathrm{s}^{-1}$

$U_{N E W}-$ conductivity of the improved vacuum system $\left(\beta_{1}=25^{\circ}, \beta_{2}=25^{\circ}\right.$ and $\left.\beta_{3}=45^{\circ}\right)$, $\mathrm{m}^{3} \cdot \mathrm{s}^{-1}$

$d$-diameter of the air pipeline of thevacuum system, $\mathrm{m}$.

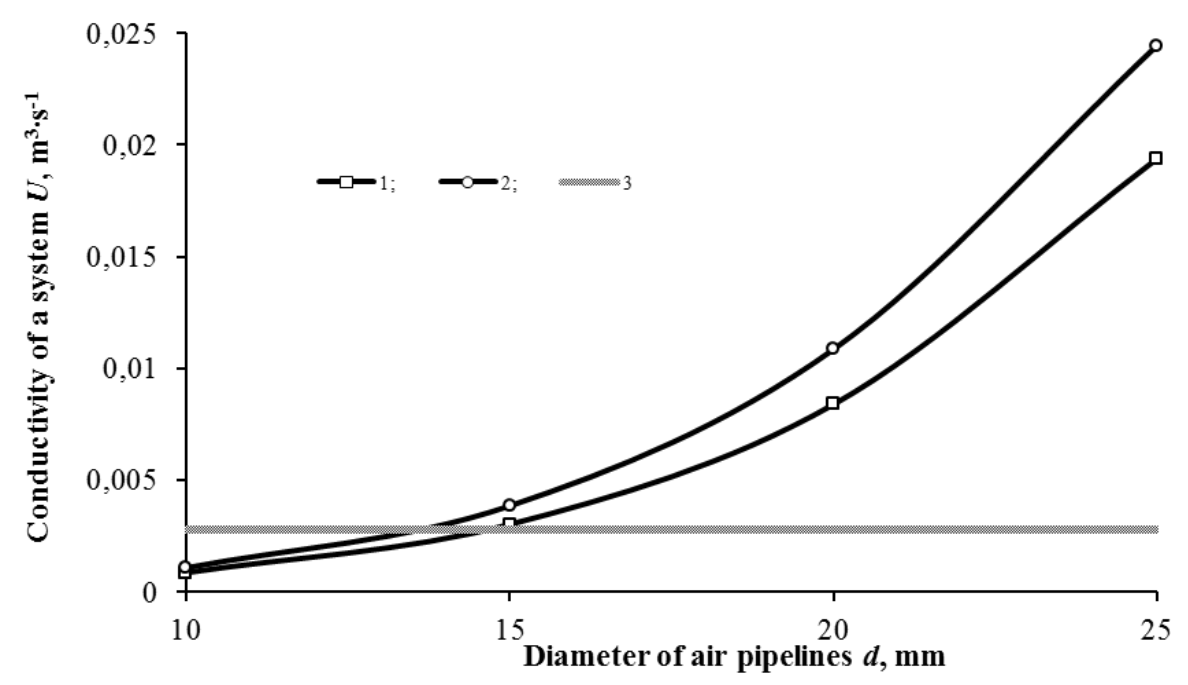

Fig. 5. Conductivity of a vacuum system of a small-size milking machine: 1 - commercial UID-10;

2 -improved version (Fig. 4, b); 3 - vacuum pump productive capacity (authors' research)

According to Fig. 5, air pipelines $10-13 \mathrm{~mm}$ in diameter have low conductivity for safe work of a small-size milking machine. It is caused by significant pressure losses. That is why a vacuum pump productive capacity will not be sufficient to replenish the pressure losses in the constructional elements. An improved design of a vacuum system (Fig. $4, b$ ) provides by $25-28 \%$ higher conductivity under the same length of air pipelines UID-10. The extended length of air pipelines has a less significant impact on the conductivity level. Thus, when the air pipeline length extends by $100 \mathrm{~mm}$, the admittance reduces only by $6-7 \%$. Pressure level at the outlet of a vacuum system determines a response rate of the vacuum system. When the admittance of the vacuum system increases, the time of setting running conditions of a small-size milking machine reduces. 


\section{Conclusions}

1. Small-size milking machines have different characteristics of the parameters of vacuum system components. The most different is the scheme of connecting the sockets of the vacuum pump and of vacuum pipeline with the vacuum tank. It can affect the effectiveness indices of the vacuum system performance, as well as of machine milking on the whole. There are no scientifically substantiated recommendations as to an optimal constructional scheme of a vacuum system of a small-size milking machine.

2. The research shows that the angle of setting of the air pipeline to the cylinder generatrix of the vacuum tank has significant effects on the air pipeline admittance. When the angle of setting $\beta_{1}=25^{\circ}$, the admittance increases by $42-45 \%$, as compared with $\beta_{1}=90^{\circ}$. It happens because pressure losses at the inlet of the hole reduce as the area of its cross-section increases.

3. The results of the experimental research show the effectiveness of an improved version of a vacuum system. The suggested constructional scheme provides by $25-28 \%$ higher admittance as compared with a commercial small-size milking machine. It corresponds with a proportional level of reducing pressure losses, which were caused by the constructional elements of the vacuum system. Higher admittance of a vacuum system of a small-size milking machine makes it possible to reduce the time of setting an operating vacuum pressure in a milk bucket.

\section{References}

[1] Медведский А. В. Влияние конструктивных параметров мобильной доильной установки на уровень вакуумметрического давления (The impact of the Constructive parameters of a mobile milking machine on the level of vacuum pressure). Motrol. Commission of motorization and energetics in agriculture, 2015, vol. 17, pp. 250-257. (In Russian).

[2] Besier J., Bruckmaier R. Vacuum levels and milk-flow-dependent vacuum drops affect machine milking performance and teat condition in dairy cows. Journal of Dairy Science, vol. 99, 2016, pp. 3096-3102.

[3] Bluemel, F. E., E. Savary, P., E. Schick M. Effects of an extended c-phase on vacuum conditions in the milking cluster. Biosystems Engineering, 2016, vol. 148, pp. 68-75. DOI: 10.1016/j.biosystemseng.2016.04.004.

[4] Besier J., Lindb O., Bruckmaier R. Dynamics of teat-end vacuum during machine milking: types, causes and impacts on teat condition and udder health - a literature review. Journal of Applied Animal Research, 2016, vol. 44, pp. 263-272.

[5] ISO 5707: 1983. Установки доильные. Конструкция и техническая характеристика. (Milking Machines. Construction and Technical Characteristics). Москва : Издательство стандартов, 1991. (In Russian).

[6] Čèsna J., Medvedskyi O., Golub G., Kukharets S. The estimation of the structural elements of conductivity of the vacuum system of a portable milking machine. 8-th International Scientific Conference Rural Development 2017 : Bioeconomy Challenges : conference proceedings, 23-24 November 2017. - Kaunas : Aleksandras Stulginskis University, 2017, pp. 237-242. DOI: http://doi.org/10.15544/RD.2017.082.

[7] Фролов С., Минайчев В., Александрова А. Вакуумная техника : справочник (Vacuum Machinery. Reference book). Москва : Машиностроение, 1992. 480 с. (In Russian).

[8] Пипко А.И., Плисковский В.Я., Пенчко Е.А. Теоретические основы вакуумной техники (Technical grounds of Vacuum Machinery). Москва : Энергоиздат, 1988. 340 c. (In Russian).

[9] Medvedskyi O., Kukharets S., Golub G., DmytrivV. Installation of equilibrium pressure of milking machine vacuum system. 17-th International Scientific Conference Engineering for Rural Development : conference proceedings, 23-25 may 2018. - Jelgava : Latvia University of Life Sciences and Technologies, 2018, vol. 17, pp. 143-148. DOI: 10.22616/ERDev2018.17.N173.

[10] Лойцянский Л.Г. Механика жидкости и газа (Mechanics of liquid and gas). Москва : Дрофа, 2003. 840 c. (In Russian).

[11] Идельчик И. Е. Справочник по гидравлическим сопротивлениям (Reference book of hydraulic resistance). Москва : Машиностроение, 1992. 672 с. (In Russian). 